\title{
A qualitative Kaupapa Māori approach to understanding infant and young child feeding practices of Māori and Pacific grandparents in Auckland, New Zealand
}

\author{
Rachel Tapera, Matire Harwood and Anneka Anderson* \\ Te Kupenga Hauora Māori, Faculty of Medical and Health Sciences, University of Auckland, Private Bag 92019, \\ Auckland 1142, New Zealand
}

Submitted 29 June 2016: Final revision received 27 September 2016: Accepted 29 September 2016: First published online 10 November 2016

\begin{abstract}
Objective: The present research sought to better understand the barriers, facilitators, attitudes and beliefs that influence the way Māori and Samoan grandparents feed their grandchildren in a deprived urban neighbourhood in New Zealand.

Design: The research adopted a qualitative methodology that was consistent with a Kaupapa Māori research approach. Seven semi-structured interviews were conducted with grandparents to collect narrative data.

Setting: Sampling occurred in one Auckland suburb. The suburb was selected because of its high level of socio-economic deprivation and ethnic diversity.

Subjects: Seven grandparents participated in the study (five Māori and two Samoan). Each participant met the inclusion criteria (i.e. they had provided at least five meals per week over the previous three months to grandchildren aged less than 24 months). Marae (i.e. meeting houses and areas used by local Māori tribes/ sub-tribes) and community organisations were used to recruit participants.

Results: A general inductive thematic analysis identified four key themes: (i) grandparents' understanding of optimal feeding practices; (ii) economic and material factors; (iii) previous experiences and customary norms; and (iv) social support and societal pressure.

Conclusions: The study showed that grandparents' complementary feeding practices in caring for infant grandchildren were influenced by upstream structural elements such as government policies related to welfare and pensions, employment, income and cultural knowledge. Frameworks that seek to achieve social justice and support cultural practices should be employed and promoted in the development of future policy and research in this area.
\end{abstract}

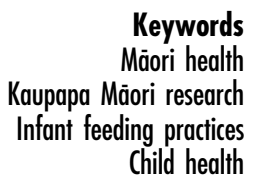

In New Zealand, the greatest and most consistent inequalities in childhood nutrition-related outcomes occur due to differences in ethnicity and/or socio-economic status. The 2002 National Children's Nutrition Survey revealed that children who identified as Māori (i.e. the indigenous people of New Zealand) and/or Pacific (i.e. people indigenous to the Pacific nations and now living in New Zealand) were more likely to be overweight and obese than children who identified as New Zealand European ${ }^{(1)}$.

Childhood malnutrition is associated with long-term health consequences, including obesity, diabetes, heart disease and cancer ${ }^{(2-5)}$. Further, these are conditions for which Māori and Pacific adults are most at risk ${ }^{(6-8)}$. Similar disparities exist between indigenous and non-indigenous children living in other developed nations (e.g. Australia, Hawaii and Canada) ${ }^{(9,10)}$ and between children living in neighbourhoods of deprivation and children living in more affluent neighbourhoods ${ }^{(11,12)}$. Previous efforts to improve childhood nutrition have sought to increase the rates and duration of breast-feeding ${ }^{(13,14)}$ or to implement interventions when children enrol in early education or school $^{(15,16)}$. To date, complementary feeding, particularly after a child's first year, has received little attention. However, optimal nutrition during the complementary feeding phase is critical, as immense nutritional changes occur when a child transitions from a milk diet to a diet that comprises a variety of foods ${ }^{(17,18)}$. Worldwide, very few children appear to receive nutritionally adequate and safe complementary foods ${ }^{(14)}$; however, the information available on this issue is limited.

Infants and young children depend on their carers for feeding. The manner in which carers provide food 
significantly affects children's nutritional intake, their health and well-being, and their relationship with food as they grow into adulthood ${ }^{(19)}$. Previous research has been conducted with parents, particularly mothers, as the primary providers of nutrition for infants ${ }^{(20)}$; however, other caregivers such as grandparents are increasingly becoming involved in infant feeding.

Grandparents are significant carers of young children in New Zealand, particularly in Māori and Pacific families $^{(21-23)}$. The role of grandparents as carers has increased for a number of reasons, including changing patterns of family formation, dissolution and re-formation ${ }^{(23)}$, changes in demographics and household structures ${ }^{(24)}$, the cost of childcare and return to work policies ${ }^{(25,26)}$. Māori and Pacific grandparents increasingly care for their grandchildren from birth (or soon thereafter) to the age of 3 years; the period in which complementary feeding commences. However, knowledge about the role of grandparents in the feeding practices of their grandchildren, particularly in relation indigenous infants, is limited.

The present research sought to better understand the barriers, facilitators, attitudes and beliefs that influence the way in which Māori and Pacific grandparents feed their grandchildren in a deprived urban neighbourhood in New Zealand. In addressing the current deficit of research on Māori and Pacific grandparents' feeding practices in New Zealand, the present research sought to contribute to the development of appropriate policies and practices and thus promote health equity for indigenous children.

\section{Methods}

The primary aim of the current study was to explore Māori and Pacific grandparents' feeding practices of infants and young children in Auckland, New Zealand to investigate and establish the factors that facilitate or hinder optimal infant feeding practices.

The research adopted qualitative methodologies and methods to gain insight into the sensitive and complex human issues that specifically drive infant feeding practices $^{(27)}$. Further, the researchers adopted a Kaupapa Māori research approach to the study. This approach was adopted to avoid victim blaming or deficit theories being applied to these already marginalised populations ${ }^{(28)}$. The Kaupapa Māori approach also ensured that the research valued and respected Te Ao Māori and mātauranga Māori (the Māori worldview and Māori way of knowing) ${ }^{(29)}$.

The study adopted a Kaupapa Māori-consistent approach (to align the research with the key principles of Kaupapa Māori theory) rather than a pure Kaupapa Māori research approach (i.e. an approach undertaken only by Māori researchers for the benefit of Māori) ${ }^{(30,31)}$. This approach was necessary because while two of the researchers identified as Māori, the principal investigator identified as Tauiwi (i.e. non-Māori) and identified as an African from Zimbabwe.

Barnes $^{(30)}$ considered whether or not researchers should identify as Māori to undertake Kaupapa Māori research and noted that issues of identification can be mitigated if investigators recognise Māori control of the research and share information and knowledge through a negotiation process. The researchers in the current study accepted this condition and control was not held by any one researcher ${ }^{(30)}$, but in partnership with senior Kaupapa Māori researchers. Further, kaumātua (i.e. respected Māori elders) provided appropriate cultural support and aided in the recruitment and formation of relationships with the participants. Kaupapa Māori research seeks to give a voice to marginalised peoples living in New Zealand ${ }^{(30,31)}$, including those disadvantaged by ethnicity or age. Consistent with this approach, the present research focused on Māori and Pacific people and the elderly and infants living in a deprived neighbourhood.

Sampling occurred in one selected suburb of Auckland, New Zealand to ensure the homogeneity of participants' deprivation experiences. New Zealand Deprivation (NZDep) is a measure of deprivation that uses area census units and various variables, including unemployment, household income, sole parenting, educational qualifications, home ownership, home living space, receiving means-tested benefits, and car and telephone access, to determine mesh-area levels of deprivation ${ }^{(32)}$. Under this measure, a suburb was selected that had the highest level of deprivation at the time that the research was undertaken. This suburb was also home to an ethnically diverse community with a relatively large proportion of Māori and Pacific peoples.

Grandparents from the suburb had to meet the entry criteria to be eligible to participate in the study. The main criterion was that the grandparents had to have provided at least five meals per week over the previous three months to grandchildren aged less than 24 months. The researchers assumed that the criterion of providing at least five meals per week would be sufficient to establish the behaviours and routines associated with feeding infants and young children.

Eligible participants were recruited through the local marae (i.e. meeting houses and areas for local Māori tribes/sub-tribes), community organisations and support groups. The marae and local organisations contacted eligible participants, provided them with information about the study and asked them if they would be interested in participating. The marae referred two Mãori participants and the local community organisations and support groups referred three Māori and two Samoan participants. The contact details of all consenting prospective participants were provided to the lead researcher, who then contacted the prospective participants over the telephone, provided detailed information about the research and answered any questions. Once the 
prospective participants had agreed to participate in the study, interview appointments were set.

Interviews with consenting participants were conducted over a three-month period. The interviews lasted less than an hour and were conducted at the participants' homes. Written informed consent was obtained from each participant before the interview commenced. Each interview was audio recorded using a Sony ICD-PX720 voice recorder.

The interviews were semi-structured to facilitate an open and flexible two-way communication that permitted new ideas to be presented during the dialogue ${ }^{(33)}$. A semistructured interview guide was developed for the research, comprising open-ended, neutral, simple and clear questions.

A general inductive approach was used to analyse the data and identify and produce categories or themes relevant to the research objectives ${ }^{(34)}$. A robust data analysis process was undertaken that included identifying, coding and categorising patterns or themes found in the data. The initial data analysis occurred at the same time as the data collection. This allowed the researcher to amend questions, develop new questions and remove unnecessary questions as she learnt more about the participant ${ }^{(33)}$. Finally, the Williams' model $^{(35,36)}$ was incorporated into the analysis process to identify the basic causes and structural elements that determined feeding practices rather than individual or surface causes.

The study received ethical approval from the University of Auckland Human Participants Ethics Committee in 2013 (reference number 010774).

\section{Results}

The data were collected from interviews with seven participants (i.e. five Māori and two Samoan participants). All participants were women aged 50 years or older who resided within the selected deprived suburb of Auckland, New Zealand (see Table 1). Participants were not employed at the time of the research; however, two participants did indicate that they were seeking employment. The majority of the participants were sole grandparents. Further, all of the participants were either the primary caregivers of their grandchildren or had substantive caregiving roles. The interviews were conducted from December 2013 to February 2014.

The infant feeding practices of grandparents were influenced by numerous factors; however, four predominant themes emerged from the data analysis:

1. grandparents' understanding of optimum feeding practices;

2. economic and material factors;

3. previous experiences and customary norms; and

4. social support and societal pressures.
In relation to each of the four themes, overlapping but thematically distinct sub-themes were identified.

\section{Grandparents' understanding of optimum feeding practices}

All of the participants were of the view that providing healthy food options to infants was important. The participants knew that nutrition was important for health and well-being and tried to the best of their abilities and within the constraints of their living contexts to provide healthy food to the infants and young children in their care. Participant 3 stated:

'I try to make his [i.e. the grandchild's] lunch as healthy as possible.'

Strong dichotomies emerged from participants' narratives about 'healthy' and 'unhealthy' food choices. Healthy food was usually associated with notions of familiarity and 'home' such as home cooking, food produced from home gardens and food that the participants themselves had consumed as children within their own homes and cultural contexts. Conversely, unhealthy food was associated with non-familiar and external sources such as store-bought manufactured food and fast food. As Participant 4 stated:

'Healthy is ... home cooking because you know what you are doing in the kitchen with your food. All the foods that other people are having, ah, nah.'

Similarly, fats, salts and sugars were categorised as 'unhealthy' foods, while vegetables, fruit, minerals and water were categorised as 'healthy' foods. Participants' nutritional knowledge varied; some participants had quite a specialised understanding of specific nutrients such as the importance of iron to healthy growth and development. However, the discourses remained embedded within concepts of familiarity and home. As Participant 3 stated:

'I have $p \bar{u} h \bar{a}$ which I find has the iron. And the $p \bar{u} b \bar{a}$, it always has iron that's [sic] the best greens.'

Thus, the participants were familiar with the nutritional benefits of indigenous vegetables that could be grown in home gardens (and picked from the wild), but could not usually be bought from retail food stores.

All of the participants also perceived breast-feeding to be a healthy feeding practice. Breast milk was described as the healthiest food source for infants and breast-feeding was reported to be a common practice among women and infants in the participants' families. The discourse about breast-feeding was also strongly influenced by the associated economic incentives. As Participant 7 stated:

'I rather they [i.e. the mothers] breast-feed. Easy as, and save the money, you know. It costs a lot of money to feed the kids, but breast-feeding is much healthier.' 
Table 1 Demographic characteristics of the research participants

\begin{tabular}{llllccc}
\hline & & & & \multicolumn{2}{c}{$\begin{array}{c}\text { Number of grandchildren } \\
\text { looked after (during time } \\
\text { of study) }\end{array}$} & Caregiver type \\
\hline Participant & Ethnicity & Occupation & Marital status & Household size & 4 & Primary \\
2 & Mãori & Retired & Single & 5 & 4 & Primary \\
3 & Māori & Retired & Widow & 5 & 1 & Primary \\
4 & Māori & Retired & Widow & 4 & 7 & Substantive \\
5 & Māori & Retired, seeking employment & Single & 2 & 6 & Substantive \\
6 & Māori & Retired & Married & 2 & 1 & Substantive \\
7 & Samoan & Retired & Married & 9 & 6 & Primary and substantive \\
\hline & Samoan & Retired, seeking employment & Single & 2 & &
\end{tabular}

Two key areas of knowledge were identified from participant grandparents' narratives: (i) gardening; and (ii) the need to provide different food types and practices to infants at different life stages. All of the participants had vegetable gardens at their homes and were knowledgeable about garden care and garden plants. Gardens were seen as a stable, healthy and cheap food supply and as sites of knowledge transfer (see the discussion further below in relation to customary norms). Further, participants described the importance of having knowledge of the different stages of child growth and development and which foods were suitable for consumption at these stages. The majority of the participants introduced some form of simple home-cooked vegetable as a first complementary food source and were reluctant to induce more complex food types until the infant was over 1 year old. As Participant 1 stated:

'... my first choices is to introduce him [the grandchild] to his veggies and then slowly still stick to the baby things, I won't put him on like the cereals we have until he's .... over one. I just find that sometimes it can be a bit hard on their pukus [stomach].'

Many of the participants felt that it was important to share their food knowledge and practices with their family members and the young children in their care. The grandparents felt that knowledge sharing would help the children to understand the importance of healthy food, maintaining good health and encourage them to engage in healthy eating habits. Participant 1 stated:

'I just tell them [the grandchildren], "It's good for you", I say, "This is really good, good kai [food] for you", and um the bean sprouts, when they see the bean sprouts, they know that's it, that's healthy for them, but the kids from school, they will have those in their lunches and they pick them out, so my mokos [grandchildren] will eat them [bean sprouts] and they [other schoolchildren] sit there and go, "Unuuuuurh do you like that?", and they go, "Yeah, it's good for your bones and its good for your blood".'

In addition to being community and family advocates in the promotion of healthy eating, most of the participants felt that there should be more nutrition-based health literacy resources developed and readily available to the people who need them most and that these resources should be written in their own languages (e.g. Samoan), easily understandable and use 'lay' terms. Further, some of the participants felt that 'health' experts should provide this information. Participant 5 stated:

'I am hoping that it [the information] will go and help those who really, really need it, need to read it. But there are some out there of course who can't read but if we can have, have it so that its working with maybe [experts] there will be a good outlet for them to have that out in the community so that grandparents and future grandparents are aware of the need for them to make sure that they are ... all feeding the right food.'

\section{Economic, material and structural factors affecting feeding practices}

Limited economic and material resources created the greatest barriers to grandparents adopting optimal feeding practices for the infants and young children in their care. These barriers included socio-economic deprivation, limited access to healthy food, inadequate childcare and welfare payment schemes, unemployment and increasing food prices. Each of the participants in the current study lived under socially and economically deprived conditions. They had all retired from employment, lived in an economically deprived neighbourhood and most of the participants were either single or widowed.

Each of the participants described the financial struggles they faced as they tried to live on their pensions and support the infants and young children in their care, and noted the impact of the rising cost of food. Two participants were actively seeking employment at the time of the research to try to improve their socio-economic positions; however, both these participants had been unsuccessful in their attempts to find employment (for reasons that they attributed to their age and a lack of employment opportunities). Participant 4 stated:

'Back to the jobs again. We are angry at the government ... And, okay, I think we are all in the 
same boat where we, I suppose our finances concerned. Food is gone up in the last how many years and we haven't even had a raise of three cents or anything [for pensions]. They [the government] give us another five bucks it would make a big difference. We haven't had any, so that is how sad, long faces, many of us here. Look down the street, you ask them a question they all got the same story.'

In addition to their low retirement incomes, lack of employment opportunities and the rising cost of food, many the participants in the study did not receive any form of governmental welfare support for caring for their grandchildren, as they had not gone through any 'legally recognised' custody processes. Generally, these participants had made more informal arrangements with family members to provide care to the infants and young children. The institutionalised and legal processes created additional barriers to the grandparents being able to access financial and social support sources and elicited feelings of frustration, stress and unfairness. As Participant 4 stated:

'Most of the ones [other grandparents] I have seen, they are getting money for them [their grandchildren] because the children have been given to them through courts and its easier for them, they get more money or something like that and that support. But we are not under anything, me and my grandchildren are not under anything so we are not given that support like the whatever out there is happening.'

The participants described the strategies they employed from one pension payment to the next to cope with the struggles they encountered in being able to purchase food and have enough food for themselves, the infants and children in their care, and often other family members. Some of these strategies included tight budgeting, purchasing cheap food in bulk and freezing it, and 'training' themselves to go without meat and consume minimal food so that they could provide for their grandchildren. Participant 4 noted:

'The other thing being financial struggles ... So for me I would like to have a little bit more because I worked and so it was hard for me when I stopped working. All the things weren't there anymore and we used to fill up all these cupboards, but I don't need all these cupboards now. I had to train myself again to have just the little that I have, and it's very hard, but what I had I will still share with the kids.'

The participants spoke of a common dilemma; they understood that fresh fruit and vegetables were the healthiest foods for infants, but these foods were also more expensive than cheaper, more affordable takeaway options. Some grandparents compromised by purchasing cheaper food options to ensure food security; however, others prioritised purchasing fresh fruit and vegetables in their budgets due to their perceived health benefits. Participant 2 stated:

'... the cost of food today, specially here in New Zealand, it's unreal, it's unreal, ... it's just [pause] a lot of families can't afford it honestly, especially when it comes to the healthy food, they can't afford it. They rather go to, go to McDonald's, go to get fish and chips, it's cheaper, it is I tell you. It's cheaper if you go there rather than this healthy food.'

Participants also described how their ability to access healthy foods was compromised by urban design and planning. At the time of the research, there was a high concentration of fast-food outlets in the neighbourhood, but very few healthy food outlet stores. As Participant 3 observed:

'... like [local suburb], now I know what the town is like, but every other shop there's a fish takeaway shop. Every other shop there's always takeaways and it's full of takeaways. Well that's not giving a good impression on the town itself for a start as far as I am concerned. They say, "It's healthy kai", it's not! It's fatty foods because they cook in all those fish and chips and they sell many of it down there, it's terrible. For myself that is an eye opening [sic] at [mentioned suburb name] shopping centre, there's too many takeaways, too many and there's nothing, nothing healthy about the food, healthy about it.'

Being unable to provide sufficient food for their families created feelings of sadness, anger, guilt, distress and shame in the participants. To prevent burdening their families with these concerns some of the grandparents went to great lengths to hide their food and financial insecurities. Participant 7 stated:

'But I try my very best to [provide enough food to my grandchildren] because three times a week or maybe two, twice a week or three times my three other grandchildren [who] lives [sic] down the road because the school is down this way and their house is down the other way. They come here and stay here for two days or three days and then I think, "Okay, you have to go home now because I am running out of food". I don't tell them I haven't got any food, I don't like telling them that, I just say, "Oh well, after school you guys go home, because I am doing something" or you know ...'

Participants' narratives consistently allocated both the cause and potential solution to their economic hardships and food insecurity to the New Zealand Government. Within these discourses, there were strong notions that it was the state's responsibility to be fair and promote equity, but that it had failed to do so. Participant 2 stated:

'The government could do a hell of a lot better, you know, instead of putting all the prices up, which 
they do, seems our system is all about making money and not really not looking after the people, so the government could, should, I should say should do something about the prices.'

\section{Previous experiences and customary norms}

The grandparents in the current study all held matriarchal roles in their families and communities that bestowed upon them roles and responsibilities as advisors, carers and cultural custodians. Customary norms are social practices that direct the 'mores' (i.e. ways of life) of groups and societies and interactions between individuals ${ }^{(37)}$. Durie $^{(38)}$ stated that within Māori society, the elderly are critical to customary norms, as they carry traditions, experiences, knowledge and mores from the past that they pass on to future generations. Similar notions exist for other Pacific cultures, including Samoan cultures ${ }^{(39)}$.

The participants were aware of their roles as advisors and key information sources within their families and often relayed their experiences of providing information about childcare and infant feeding practices to others. Participant 1 noted:

'His [grandchild's] mum, she will ask me, "What shall I give him mum or nana?", ok ... "Well you can try this and you can try that", but she will always take on board what I say. She will give it a go and then she will say "Nana you were right, he loves it".

The embedded relationships between food knowledge and feeding practices within broader socially constructed customary norms were evident from the participants' narratives and discourses that included their respective cultural concepts of food, gardening, recipes, remedies and delicacies. Participant 5 stated:

'Now I'm one that believed in natural foods from the garden. My favourite and I am not too sure whether the whole of New Zealand are aware that in the gardens, usually a weed called sow thistle, to Māori it's a delicacy, and it's called $p \bar{u} h \bar{a}, p-u-b-a, p \bar{u} h \bar{a}$.'

The participants explicitly discussed the pleasure and pride they felt in transferring their cultural knowledge and practices to younger family members. Some participants also perceived the generational transfer of knowledge to their grandchildren as a key strategy in the development of knowledge and social values such as leadership and pride in ethnic identity. Participant 5 asked:

'Have you heard that saying, Māori saying: "He aba te mea nui o te Ao? He tāngata! He tāngata! He tāngata! What is the most important thing in this world", even though they say, "It's people, people, people", but to me its grandchildren, grandchildren, grandchildren because they are the leaders of the world or leaders of tomorrow, yes.'
As previously stated, each participant had extensive knowledge of gardening practices and various garden plants. As well as being affordable food sources, gardens held a significant cultural and social importance to the participants, as they were sites at which cultural norms and practices were enacted and preformed. Gardens provided spaces, opportunities and activities for 'family time' between family members. They were places in which the grandparents could demonstrate applied learning skills to their grandchildren and transfer their knowledge and passion for growing vegetables. Participant 1 stated:

'... and by having my veggie garden up there, at the back, that's what encourages the kids too, coz they seed it with me, they water my garden and now go, "Oh Nana I can't wait for the beans, oh Nana look at all the lettuce, beetroot, everything".'

\section{Societal pressures and lack of support}

Despite participants' knowledge of nutrition and infant feeding practices and the valuable roles they played in advising their families on the matters, many participants noted the negative effects of social pressures and that there was lack of information and support available for them as Māori, Samoan, economically disadvantaged and aged women.

Negative social discourses around breast-feeding in New Zealand were a common concern among participants. Despite advocating for breast-feeding within their families due to its health and economic benefits, participants were aware that social pressures deterred the women in their families from breast-feeding, particularly in public. Participant 2 stated:

'Well here in New Zealand, I know we have a problem with this [breast-feeding], especially when mothers go out and they breast-feed their babies in public. There's a lot of people that moan and groan about this.'

In addition to noting a social aversion towards breastfeeding, the participants were also exposed to social judgement and openly criticised for their infant feeding practices and the care they provided to their grandchildren. Generally, comments were directed towards the quality and quantity of food they provided to the infants and children in their care, but some comments were also directed towards the children's body size. Participant 1 stated:

'My mokos [grandchildren] are skinny and people say to me, "Your mokos are skinny, don't you feed them?"'

Participant 1 described having intense feelings of shame and guilt for not being perceived as taking adequate care of her 'skinny' grandchildren. She described how the 
comment caused her to provide more 'fattening' and less healthy foods to her grandchildren.

The participants felt that the effects of societal pressure on infant feeding practices could be improved with better information sources and by more social support being provided to families and extended families. Participant 5 stated:

'... surely that [support] would have come from their extended family, they should be helping them all. If I say I am a caring grandmother, I can't speak for the other grandparents, they, maybe the information should not only go to the nursing mothers, it should go to the extended family.'

The majority of participants felt that their families needed more information and support on infant feeding practices; however, they also felt that they currently had to fill these gaps and this constant pressure led to feelings of fatigue and frustration. One participant suggested that to avoid the exhaustion of 'having to do it all without support for me', the government and local health groups should be taking more responsibility. Participant 4 stated:

'Like today, I could have been help to somebody out there. But because I am negative, I feel negative because there's not enough support out there uuuum, and I am not getting any so why should I give anything back?

\section{Discussion}

The complementary feeding practices of grandparents caring for infant grandchildren are influenced by upstream structural elements such as employment, income, cultural knowledge and government policies related to welfare and pensions. The Māori and Samoan grandparent participants interviewed in the current study possessed a great understanding and appreciation of the effect of food on the well-being of children. However, despite this knowledge, the participants felt limited by economic and material factors and identified financial struggles, unemployment and food prices as key barriers to their providing better feeding practices. The roles of grandparents' previous experiences (i.e. their upbringings and observations) and 'customary norms' on feeding practices were also important. Further, the social context in which the grandparents lived was also highly influential, as the effects of family support and societal pressure influenced choices and behaviours.

As much as an individual's behaviours (in this instance, feeding behaviours) are said to influence their own health outcomes and the health outcomes of those in their care $^{(40)}$, an individual may not have complete control over the structural or system drivers that define their current living conditions. Individual or personal factors such as education levels, employment status, income and cultural differences are often considered the main causes of poor feeding practices and diet-related outcomes ${ }^{(41-43)}$. However, complex and profound environmental and contextual mechanisms can lead to both good and bad nutrition-related outcomes. Williams ${ }^{(35,44)}$ suggested that these 'invisible forces' are in fact the 'basic causes' of health inequities.

Applying Williams' model to the findings of the present study, one can see that his posited 'basic causes' of racism and economic and legal structures ${ }^{(35,36,44)}$ affect the nutrition-related choices and behaviours of Māori and Samoan grandparents caring for their grandchildren. As shown in Fig. 1, economic and legal structures (e.g. the policies that affect caregivers, childcare, food prices, financial benefits and the rights of the elderly), colonial processes and societal attitudes towards ageism, racism and sexism can contribute individually or collectively to and have a flow-on effect on current social status (including socio-economic status and educational attainment). This in turn affects surface causes such as stress or psychosocial resources. Further, these structures ultimately impact health-related behaviours and choices (in this case, grandparents' infant feeding practices) and thus the health status of children.

The generalisability of the present study's findings is limited. However, the study identified new information that will be useful to policy makers, funders and services working with the caregivers of young children. Further,

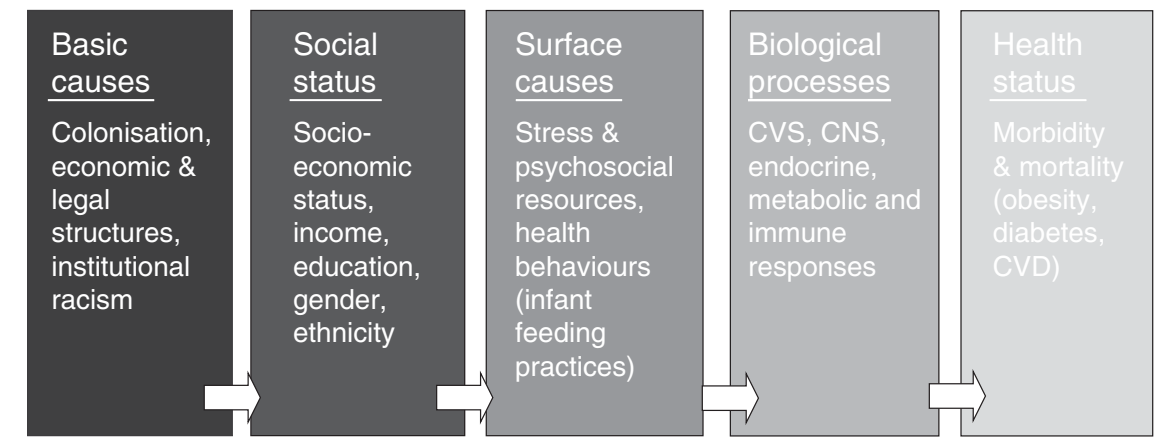

Fig. 1 The basic and surface causes of health inequalities: a conceptual model (adapted from Williams ${ }^{(35,44)}$; CVS, cardiovascular system; CNS, central nervous system) 
the study highlighted the issues facing older and indigenous caregivers who are not employed and live in urban settings.

There were also limitations in the study's methodology. A Kaupapa Māori-consistent approach rather than a pure Kaupapa Māori research approach was adopted. The research was consistent with Kaupapa Māori, as the Tauiwi or non-Māori researcher was supervised by senior Māori academics and guided on protocol and culture by kaumātua (i.e. elders). The study also explored an area that has received little attention and engaged and gave a voice to marginalised populations. Alignment in these areas ensured that a robust and culturally safe method of analysis and interpretation was adopted.

Finally, while the research considered only the perceptions of grandparents, it uncovered poignant stories of the hardships experienced by grandparents as they tried to do their best for their grandchildren. An analysis of their interviews was undertaken to deconstruct the victim blaming that often pervades the discourse on nutrition and health outcomes of Māori and Pacific children living in poverty. The study shifted focus from the children and their families to societal, structural and service factors.

The current relatively small study provided rich and meaningful information about the infant feeding practices of Māori and Pacific grandparents living in a deprived urban neighbourhood. Kaupapa Māori research enabled a comprehensive social justice approach to focus on the welfare of infants, young children and the elderly in relation to the availability and accessibility of food while applying indigenous ethical standards and practices. Future policies and research in this area should employ and promote similar frameworks that seek to achieve social justice and support cultural knowledge and practices.

\section{Acknowledgements}

Acknowledgements: The authors would first like to acknowledge all the grandparents who participated in the research for making the time to speak with them and sharing their experiences and narratives. They would also like to express their gratitude to their kuia kaumätua, Whaea Julie Wade, for her wisdom and guidance. Finally, they thank Ruapotaka Marae and Grandparents Raising Grandchildren for their contribution and support for this research. Financial support: This research received no specific grant from any funding agency in the public, commercial or not-for-profit sectors. Conflict of interest: None. Authorship: This paper was based on a Masters of Public Health thesis undertaken by the lead author, R.T. M.H. and A.A. were the academic supervisors of this research project and lead Kaupapa Māori academics. M.H. and A.A. guided R.T. through the project design, CO-analysed the data and assisted with the writing, editing and theoretical development of this paper. Ethics of buman subject participation: This study was conducted according to the guidelines laid down in the Declaration of Helsinki and all procedures involving human subjects/patients were approved by the University of Auckland Human Participants Ethics Committee (UAHPEC). Written consent was obtained from all subjects/patients.

\section{References}

1. Parnell W, Scragg R, Wilson N et al. (2003) NZ Food NZ Children. Key Results of the 2002 National Children's Nutrition Survey. Wellington: Ministry of Health.

2. Calle E \& Kaaks R (2004) Overweight, obesity and cancer: epidemiological evidence and proposed mechanisms. Nat Rev Cancer 4, 579-591.

3. Hossain P, Kawar B \& Nahas ME (2007) Obesity and diabetes in the developing world - a growing challenge. $N$ Engl J Med 356, 213-215.

4. Yang Z \& Huffman SL (2013) Nutrition in pregnancy and early childhood and associations with obesity in developing countries. Matern Child Nutr 9, 105-119.

5. Thompson AL (2012) Developmental origins of obesity: early feeding environments, infant growth, and the intestinal microbiome. Am J Hum Biol 24, 350-360.

6. Joshy G \& Simmons D (2006) Epidemiology of diabetes in New Zealand: revisit to a changing landscape. NZ Med J 119, 90-145.

7. Chan WC, Wright C, Riddell T et al. (2008) Ethnic and socioeconomic disparities in the prevalence of cardiovascular disease in New Zealand. $N Z$ Med J 121, 11-20.

8. Jeffreys M, Stevanovic V \& Tobias M (2004) Ethnic inequalities in cancer survival in New Zealand: linkage study. Aust J Public Health 95, 834-837.

9. Anderson I, Crengle S, Kamaka ML et al. (2004) Indigenous health in Australia, New Zealand and the Pacific. Lancet 367, 1775-1785.

10. Kuhnlein HV, Reoveur O, Soueida R et al. (2004) Arctic Indigenous peoples experience the nutrition transition with changing dietary patterns and obesity. J Nutr 134, 1447-1453.

11. Danielzik S, Czerwinski-Mast M, Langnäse K et al. (2004) Parental overweight, socioeconomic status and high birth weight are the major determinants of overweight and obesity in 5-7 y-old children: baseline data of the Kiel Obesity Prevention Study (KOPS). Int J Obes Relat Metab Disord 28, 1494-1502.

12. Devaux M \& Sass F (2011) Social inequalities in obesity and overweight in 11 OECD countries. Eur J Public Health 23, 464-469.

13. World Health Organization (2000) Obesity: Preventing and Managing the Global Epidemic. Report of a WHO Consultation, WHO Technical Support Series no. 894. Geneva: WHO.

14. World Health Organization (2003) Global Strategy for Infant and Young Child Feeding. Geneva: WHO.

15. Brown T \& Summerbell C (2008) Systematic review of school-based interventions that focus on changing dietary intake and physical activity levels to prevent childhood obesity: an update to the obesity guidance produced by the National Institute for Health and Clinical Excellence. Obes Rev 10, 110-141.

16. Cauwenberghe EV, Maes L, Spittaels H et al. (2010) Effectiveness of school-based interventions in Europe to promote healthy nutrition in children and adolescents: systematic review of published and 'grey' literature. Br J Nutr 103, 781-797. 
17. Flores Huerta S (2011) Importance of infant feeding during the first year of life. Gac Med Mex 147, 22-31.

18. Ministry of Health (2012) Food and Nutrition Guidelines for Healthy Infants and Toddlers (Aged 0-2 Years): A Background Paper, 4th ed. Wellington: Ministry of Health.

19. Kral TV \& Rauh EM (2010) Eating behaviors of children in the context of their family environment. Physiol Behav $\mathbf{1 0 0}$, 567-573.

20. Glover M, Manaena-Biddle H \& Waldon J (2007) Influences that affect Māori women breastfeeding. Breastfeeding Rev 15, 5-14.

21. Pinson-Milburn NM, Fabian ES, Schlossberg NK et al. (1996) Grandparents raising grandchildren. J Couns Dev 74, 548-554.

22. Statistics New Zealand (2010) New Zealand Childcare Survey 2009. http://www.stats.govt.nz/browse_for_stats/ people_and_communities/Children/ChildcareSurvey_HOTP 2009revised.aspx (accessed March 2015).

23. Worrall J (2009) Grandparents and Whanau/Extended Families Raising Kin Children in Aotearoa/New Zealand. Auckland: Grandparents Raising Grandchildren Trust.

24. Families Commission (2005) Focus on Families: Reinforcing the Importance of Family. Wellington: Families Commission.

25. Morrow-Kondos D, Weber JA, Cooper K et al. (1997) Becoming parents again. J Gerontol Soc Work 28, 1-2.

26. Wheelock J \& Jones K (2002) 'Grandparents are the next best thing': informal childcare for working parents in urban Britain. J Soc Policy 31, 441-463.

27. Marshall MN (1996) Sampling for qualitative research. Fam Pract 13, 522-526.

28. Reid P \& Robson B (2006) State of the Maori Nation: Twenty-First-Century Issues in Aotearoa. Auckland: Reed.

29. Smith GD, Dorling D, Gordon D et al. (1999) The widening health gap: what are the solutions? Crit Public Health 9, 151-170.

30. Barnes HM (2000) Kaupapa Māori: explaining the ordinary. Pac Health Dialog 7, 13-16.
31. Walker S, Eketone A \& Gibbs A (2006) An exploration of Kaupapa Maori research, its principles, processes and applications. Int J Soc Res Methodol 9, 331-344.

32. White PS (2008) Atlas of Socioeconomic Deprivation in New Zealand: NZDep2006. Wellington: Ministry of Health.

33. DiCicco-Bloom B \& Crabtree BF (2006) The qualitative research interview. Med Educ 40, 314-321.

34. Thomas DR (2006) A general inductive approach for analyzing qualitative evaluation data. Am J Eval 27, 237-246.

35. Williams DR \& Mohammed SA (2013) Racism and health. I: Pathways and scientific evidence. Am Behav Sci 57, $1152-1173$.

36. Mills C (2010) Health, employment and recession. The impact of the global crisis on health inequities in New Zealand. Policy Quart 6, 53-59.

37. Bicchieri C (2006) The Grammar of Society. Cambridge: Cambridge University Press.

38. Durie M (2001) Mauri ora: The Dynamics of Māori Health. Oxford: Oxford University Press.

39. Tamasese TK, Parsons TL \& Waldegrave C (2014) Pacific Perspectives on Aging in New Zealand. Pacific-focused Qualitative Research Prepared for the New Zealand Longitudinal Study of Aging (NZLSA). Christchurch: The Family Centre.

40. Popay J, Williams G, Thomas G et al. (1998) Theorising inequalities in health: the place of lay knowledge. Sociol Health Illn 20, 619-644.

41. Cummins S \& Macintyre S (2006) Food environments and obesity - neighbourhood or nation? Int J Epidemiol 35, 100-104.

42. Hill JO \& Peters JC (1998) Environmental contributions to the obesity epidemic. Science 280, 1371-1374.

43. Macintyre S (2007) Deprivation amplification revisited; or, is it always true that poorer places have poorer access to resources for healthy diets and physical activity? Int J Behav Nutr Phys 4, 32.

44. Williams DR (1997) Race and health: basic questions, emerging directions. Ann Epidemiol 7, 322-333. 